\title{
Splenectomy increases the survival time of heart allograft via developing immune tolerance
}

\author{
Jinguo Zhu', Shuzhen Chen ${ }^{4}$, Jinju Wang ${ }^{4}$, Cheng Zhang ${ }^{4}$, Wei Zhang ${ }^{3}$, Peng Liu ${ }^{2}$, Ruilian Ma ${ }^{2,4}$,
} Yanfang Chen ${ }^{4^{*}}$ and Zhen $\mathrm{YaO}^{2^{*}}$

\begin{abstract}
Background: The spleen is an active lymphoid organ. The effect of splenectomy on the immune response remains unclear. This study investigated whether splenectomy can induce immune tolerance and has a beneficial role in cardiac allograft.

Methods: Wistar rats were used for heart donors. The Sprague-Dawley (SD) rats designated as the recipients of heart transplantation $(H T)$ were randomly assigned into four groups: sham, splenectomy, HT, splenectomy $+H T$. The survival of transplanted hearts was assessed by daily checking of abdominal palpation. At various time points after transplantation, the transplanted hearts were collected and histologically examined; the level of $\mathrm{CD}_{4}{ }^{+} \mathrm{CD}_{25}{ }^{+} \mathrm{T}$ regulatory lymphocytes (Tregs) and rate of lymphocyte apoptosis (annexin- $\mathrm{v}^{+} \mathrm{Pl}^{+}$cells) in the blood were analyzed by using flow cytometric method.

Results: 1) Splenectomy significantly prolonged the mean survival time of heart allografts ( $7 \pm 1.1$ days and $27 \pm 1.5$ days for $H T$ and splenectomy $+H T$, respectively; $n=12-14$ /group, $H T$ vs. splenectomy $+H T, p<0.001) ; 2$ ) Splenectomy delayed pathological changes (inflammatory cell infiltration, myocardial damage) of the transplanted hearts in splenectomy $+\mathrm{HT}$ rats; 3) The level of $\mathrm{CD}_{4}{ }^{+} \mathrm{CD}_{25}{ }^{+}$Tregs in the blood of splenectomized rats was significantly increased within 7 days (2.4 \pm $0.5 \%, 4.9 \pm 1.3 \%$ and $5.3 \pm 1.0 \%$ for sham, splenectomy and splenectomy $+H T$, respectively; $n=15$ /group, sham vs. splenectomy or splenectomy $+H T, p<0.05$ ) after splenectomy surgery and gradually decreased to baseline level; 4) Splenectomy increased the rate of lymphocyte apoptosis (day 7: $0.3 \pm 0.05 \%, 3.9 \pm 0.9 \%$ and $4.1 \pm 0.9 \%$ for sham, splenectomy and splenectomy $+H T$, respectively; $n=15 /$ group, sham vs. splenectomy or splenectomy $+H T, p<0.05$ ) in a pattern similar to the change of the $\mathrm{CD}_{4}{ }^{+} \mathrm{CD}_{25}{ }^{+}$Tregs in the blood.

Conclusions: Splenectomy inhibits the development of pathology and prolongs the survival time of cardiac allograft. The responsible mechanism is associated with induction of immune tolerance via elevating $\mathrm{CD}_{4}{ }^{+} \mathrm{CD}_{25}{ }^{+}$Tregs and increasing lymphocyte apoptosis.
\end{abstract}

Keywords: Splenectomy, Heart transplantation, Immune tolerance, $\mathrm{CD}_{4}{ }^{+} \mathrm{CD}_{25}{ }^{+}$Treg, Lymphocyte apoptosis

\section{Background}

Cardiac transplantation is the preferred surgical therapy for patients with end-stage heart diseases. However, allograft rejection is the major challenge for the transplantation [1]. To date, several strategies have been made towards preservation of the transplanted heart by regulating the immune response of the recipients. These include

\footnotetext{
* Correspondence: yanfang.chen@wright.edu; yaozhen62@hotmail.com ${ }^{4}$ Department of Pharmacology and Toxicology, Boonshoft School of Medicine of Wright State University, Dayton, OH 45435, USA

${ }^{2}$ Department of Cardiology, The People's Hospital of Sanya, Sanya, Hainan 572000, China

Full list of author information is available at the end of the article
}

administration of immunosuppressive drugs [2] and generation of tolerogenic dendritic cells [3]. Nevertheless, the obstacle such as the adverse effects jeopardizes the clinical application [4]. Therefore, new avenues are demanded for successful cardiac transplantation.

Transplant immune tolerance is defined as a lack of transplant rejection in the recipient in the absence of immunosuppressive agents. $\mathrm{CD} 4{ }^{+} \mathrm{CD} 25^{+}$Tregs are a minor subset $(5-10 \%)$ of $\mathrm{CD} 4^{+} \mathrm{T}$ cells, arising in the thymus. Accumulating data showed that the $\mathrm{CD} 4^{+} \mathrm{CD} 25^{+}$Tregs potentially contribute to the development of transplant immune tolerance. For example, Sakaguchi and colleagues

\section{Biomed Central}

(c) 2013 Zhu et al.; licensee BioMed Central Ltd. This is an Open Access article distributed under the terms of the Creative Commons Attribution License (http://creativecommons.org/licenses/by/2.0), which permits unrestricted use, distribution, and reproduction in any medium, provided the original work is properly cited. 
reported that removal of $\mathrm{CD} 44^{+} \mathrm{CD} 25^{+}$Tregs from normal mice reduced the survival of the grafts [5]. Graca et al. [6] demonstrated that $\mathrm{CD} 4^{+} \mathrm{CD} 25^{+}$Tregs are the principle regulator of transplantation tolerance by suppressing the active $\mathrm{T}$ cells.

The spleen is the largest single lymphoid organ in the body. It plays a critical role in the immune response. Several studies have investigated the effects of splenectomy on the immune system. Thomas et al. [7] showed that splenectomy prevented the hyperacute rejection of rabbit renal allograft. Carobbi and colleagues [8] found that splenectomy increased the survival rate of cardiac xenograft by blocking the humoral antibody response. However, the effect of splenectomy on immune tolerance of cardiac transplantation remains unclear.

The objective of this study was to determine whether splenectomy can increase the survive time of heart allograft by developing immune tolerance via augmenting Tregs and increasing lymphocyte apoptosis.

\section{Methods \\ Animals}

Adult Wistar and Sprague-Dawley (SD) rats (weight, $250-300 \mathrm{~g}$ ) were used as donors and recipients, respectively. All rats were purchased from the Medical Experimental Animal Center of Sun Yat-sen University and housed in the animal care facility at Sun Yat-sen University. All rats were kept under standard temperature, humidity, and time light conditions and fed standard chow and water ad libitum. All experimental protocols were reviewed and approved by the Institutional Animal Care and Use Committee of Sun Yat-sen University.

\section{Experiment groups}

All SD rats were randomly assigned to four groups ( $n=15$ /group): sham; splenectomy; HT; splenectomy + HT.

\section{Splenectomy and heterotopic heart transplantation}

In the sham group, the SD rats underwent laparotomy only. In splenectomy and splenectomy $+\mathrm{HT}$ groups, the splenectomy surgery was performed according to a previous published method [9]. Briefly, the rats were anaesthetized by a single intraperitoneal injection of ketamine/xylazine $(100: 10 \mu \mathrm{g} / \mathrm{kg})$. After the spleen was surgically exposed and Hilar vessels were clamped, the spleen was removed and the vessel stump was ligated with suture. In HT and splenectomy + HT groups, hearts from Wistar rats (donors) were transplanted into SD rats (recipients) as previously reported with slight modifications [10-12]. In brief, the SD rats were anaesthetized as above described. A midline incision was made on the abdominal wall. By using standard vascular microsurgical techniques, the recipient's abdominal aorta was anastomosed end-to-side to the donor's abdominal aorta and the recipient's inferior vena cava was anastomosed to the donor's pulmonary artery. Graft survival was monitored by daily checking of palpable heartbeat. Graft rejection was defined as the cessation of heartbeat.

\section{Isolation of mononuclear cells from peripheral blood}

A volume of 0.3-0.5 $\mathrm{ml}$ of peripheral blood was taken into a sterile heparinized syringe from the caudal vein of the SD rats in sham, splenectomy, and splenectomy + HT groups at various time points (day 1, 3, 5, 7, 15, 20, and 28) after sham or splenectomy surgery, or from the SD rats in HT group at day 1, 3, 5, and 7 after HT transplantation surgery. The peripheral blood mononuclear cells (PBMCs) were prepared by gradient density centrifugation as we described previously with slight modifications [13]. Briefly, blood was diluted in $2 \mathrm{ml}$ PBS and then gently layered over equal volume of gradient medium (Hisopaque-1083, Sigma, Fairfax, VA) for centrifugation at $800 \mathrm{~g}$ for $30 \mathrm{mins}$ at $4^{\circ} \mathrm{C}$. The PBMCs in the interface layer were transferred to a new tube, washed with PBS, centrifuged at $400 \mathrm{~g}$ for 5 mins at $4{ }^{\circ} \mathrm{C}$ and used for flow cytometric analysis.

\section{Analysis of $\mathrm{CD} 4{ }^{+} \mathrm{CD} 25^{+}$Tregs by flow cytometry}

The Tregs were identified by double positive expression of membrane specific markers CD4 and CD25. The percentage of $\mathrm{CD} 4{ }^{+} \mathrm{CD} 25^{+}$Tregs in the peripheral blood from all experiment groups was analyzed at different time points (day 1, 3, 5, 7, 15, 20, and 28). The PBMCs were collected as described above and resuspended with PBS and incubated with FITC-conjugated anti-rat CD4 (eBioscience, San Diego, CA) and PE-conjugated anti-rat CD25 (eBioscience, San Diego, CA) antibodies for 30 mins at $4^{\circ} \mathrm{C}$ in the dark. Isotype matched (IgG) nonspecific antibodies served as negative controls. The concentrations of antibodies were applied according to manufacture instructions. A total of at least 10000 events were collected and analyzed by using Accuri C6 flow cytometer and CFlow Plus Analysis software (Ann Arbor, MI). A live lymphocyte gate was created on dot plots using forward scatter and side scatter plots. The percentage of Tregs was determined within the settled gate by double positive staining of CD4 and CD25.

\section{Analysis of lymphocyte apoptosis by flow cytometry}

At different time points (day 1, 3, 5, 7, 15, 20, and 28), the PBMCs were collected from all experimental groups as described above to assess lymphocyte apoptosis. Apoptosis was measured by detecting phosphatidylserine externalization in the cell membrane using the annexin$\mathrm{v} /$ propidium iodide (PI) assay. In brief, the collected cells were washed twice with cold PBS, centrifuged, resuspended in $100 \mu \mathrm{l}$ of binding buffer containing $5 \mu \mathrm{l}$ FITC-conjugated annexin-v (Invitrogen, Carlsbad, CA) 
and $2 \mu \mathrm{l} 100 \mu \mathrm{g} / \mathrm{ml}$ PI (Invitrogen, Carlsbad, CA) and incubated for 15 mins at room temperature in the dark. Isotype matched (IgG) non-specific antibodies served as negative controls. The concentrations of antibodies were applied according to manufacture instructions. A total of at least 10000 events were collected and analyzed by using Accuri C6 flow cytometer and CFlow Plus Analysis software (Ann Arbor, MI). A live lymphocyte gate was created on dot plots using forward scatter and side scatter plots. The rate of lymphocyte apoptosis was determined within the settled gate by double positive staining of annexin-v and PI.

\section{Histological examination of heart}

The heart samples were collected from either splenectomy group or splenectomy + HT group. The heart samples harvested from donor rats served as the control group. All tissue samples were fixed in $4 \%$ buffered formalin solution overnight, embedded in paraffin, sectioned (5-6 $\mu \mathrm{m}$ thickness) under a microtome, and stained with hematoxylin and eosin (H\&E) by using the standard method. All samples were analyzed under light microscopy in a blinded fashion.

\section{Statistical analysis}

Data were expressed as mean \pm SEM. Means for two groups were compared using Student's $t$-test. Multiple comparisons were performed by one-way ANOVA. Graft survival was plotted using Kaplan-Meier method, and allograft survival rates were analyzed by using the log-rank test. $P$ values $<0.05$ were considered statistically significant.

\section{Results}

\section{Splenectomy prolongs the mean survival time of heart allografts}

The representative images of heart transplantation are presented in Figure 1. The survival time of transplanted hearts in HT group was $7 \pm 1.1$ days $(n=12)$, while the survival time of transplanted hearts in splenectomy+ HT group was $27 \pm 1.5$ days $(n=14)$. The data showed that the mean survival time of heart allograft in splenectomized rats was significantly longer $(P<0.001)$ than that in non-splenectomy rats (Figure 2).

\section{The level of $\mathrm{CD}^{+} \mathrm{CD}^{+} 5^{+}$Tregs was increased in splenectomized rats}

The $\mathrm{CD} 4^{+} \mathrm{CD} 25^{+}$Tregs in the PBMCs were determined by using the flow cytometry method. In the forward and side scatter plots, the typical lymphocyte population identified on basis of size and granularity was presented and a gate (R1) was set (Figure 3A). Representative flow cytometric panels showed the percentage of $\mathrm{CD} 4^{+} \mathrm{CD} 25^{+}$Tregs within the gate (R1) in all experimental groups (Figure 3B-E) at day 5 after transplantation. We observed that there was a higher percentage of $\mathrm{CD} 4{ }^{+} \mathrm{CD} 25^{+}$Tregs (present in the

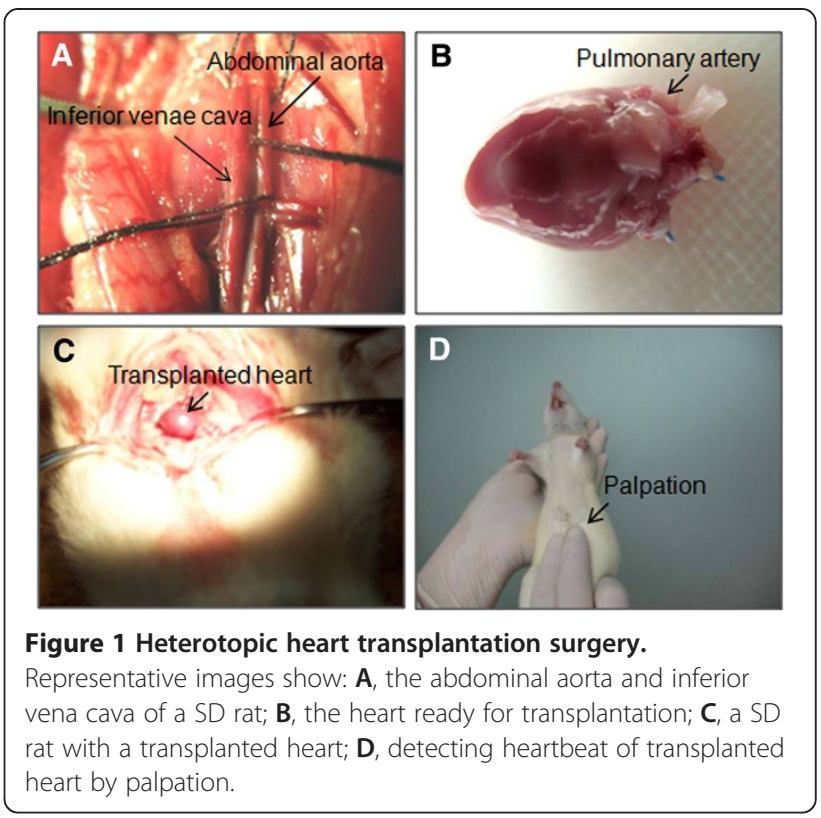

upper right of the quarternary plot) in splenectomy and splenectomy $+\mathrm{HT}$ groups at day 5 . Flow cytometric analysis revealed that the percentage of $\mathrm{CD} 4{ }^{+} \mathrm{CD} 25^{+}$Tregs was increased on day 3,5 , and 7 after splenectomy surgery (day 7 : $2.4 \pm 0.5 \%, 4.9 \pm 1.3 \%$ and $5.3 \pm 1.0 \%$ for sham, splenectomy and splenectomy $+\mathrm{HT}$, respectively; $\mathrm{n}=15$ /group, sham $v$. splenectomy or splenectomy $+\mathrm{HT}, \mathrm{p}<0.05$ ). Then, the level of $\mathrm{CD} 4^{+} \mathrm{CD} 25^{+}$Tregs in recipient rats was gradually decreased to baseline level on day $28(2.4 \pm 0.5 \%, 2.4 \pm 0.5 \%$ and $2.5 \pm 0.5 \%$ for sham, splenectomy and splenectomy +

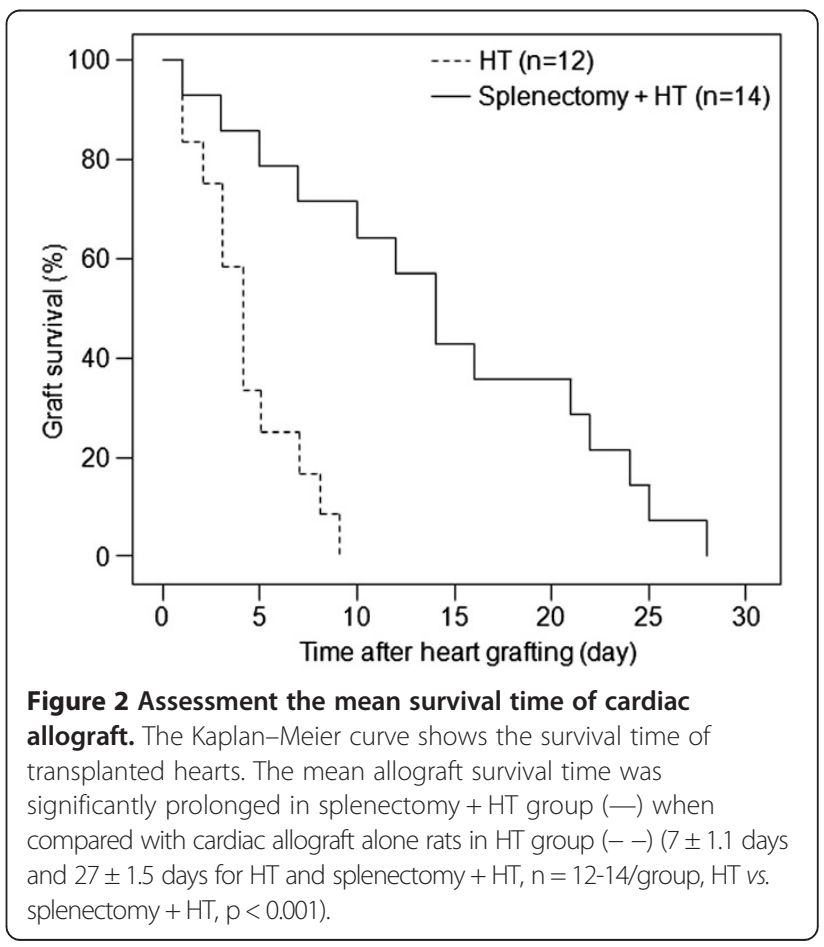




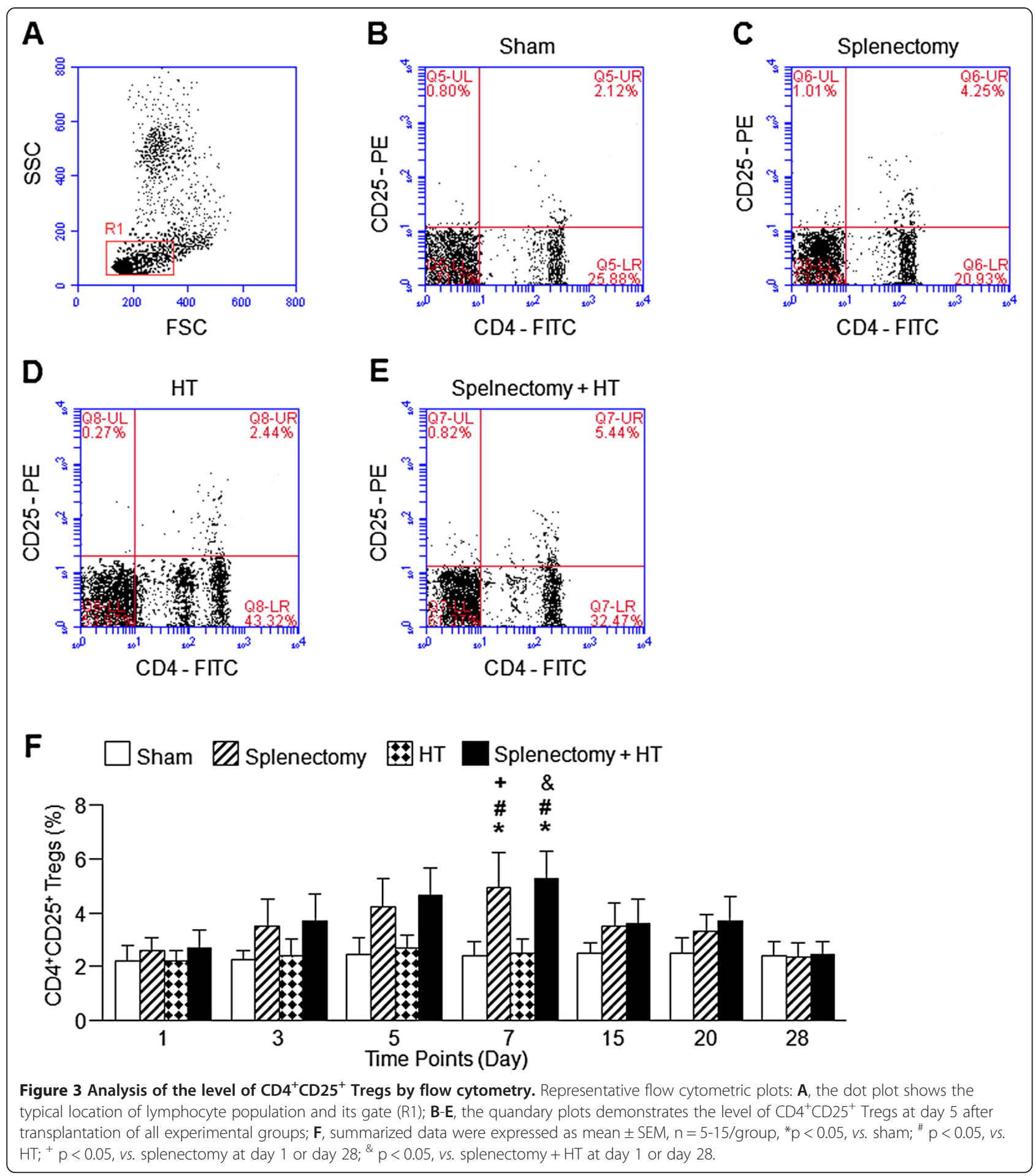

HT, respectively; $n=5$ /group, sham vs. splenectomy or splenectomy $+\mathrm{HT}, \mathrm{p}>0.05$ ). There were neither significant differences in the levels of $\mathrm{CD} 4{ }^{+} \mathrm{CD} 25^{+}$Tregs between sham and HT groups, nor between splenectomy and splenectomy + HT groups, indicating heart transplantation alone had no effect on the $\mathrm{CD} 4^{+} \mathrm{CD} 25^{+}$Tregs level. These data were summarized in Figure 3F.
The lymphocyte apoptotic rate was increased in splenectomized rats

In all experimental groups, the apoptotic rate in lymphocytes was analyzed by the flow cytometry method. In the forward and side scatter plots, the typical lymphocyte population identified on basis of size and granularity was presented and a gate (R3) was set (Figure 4A). 


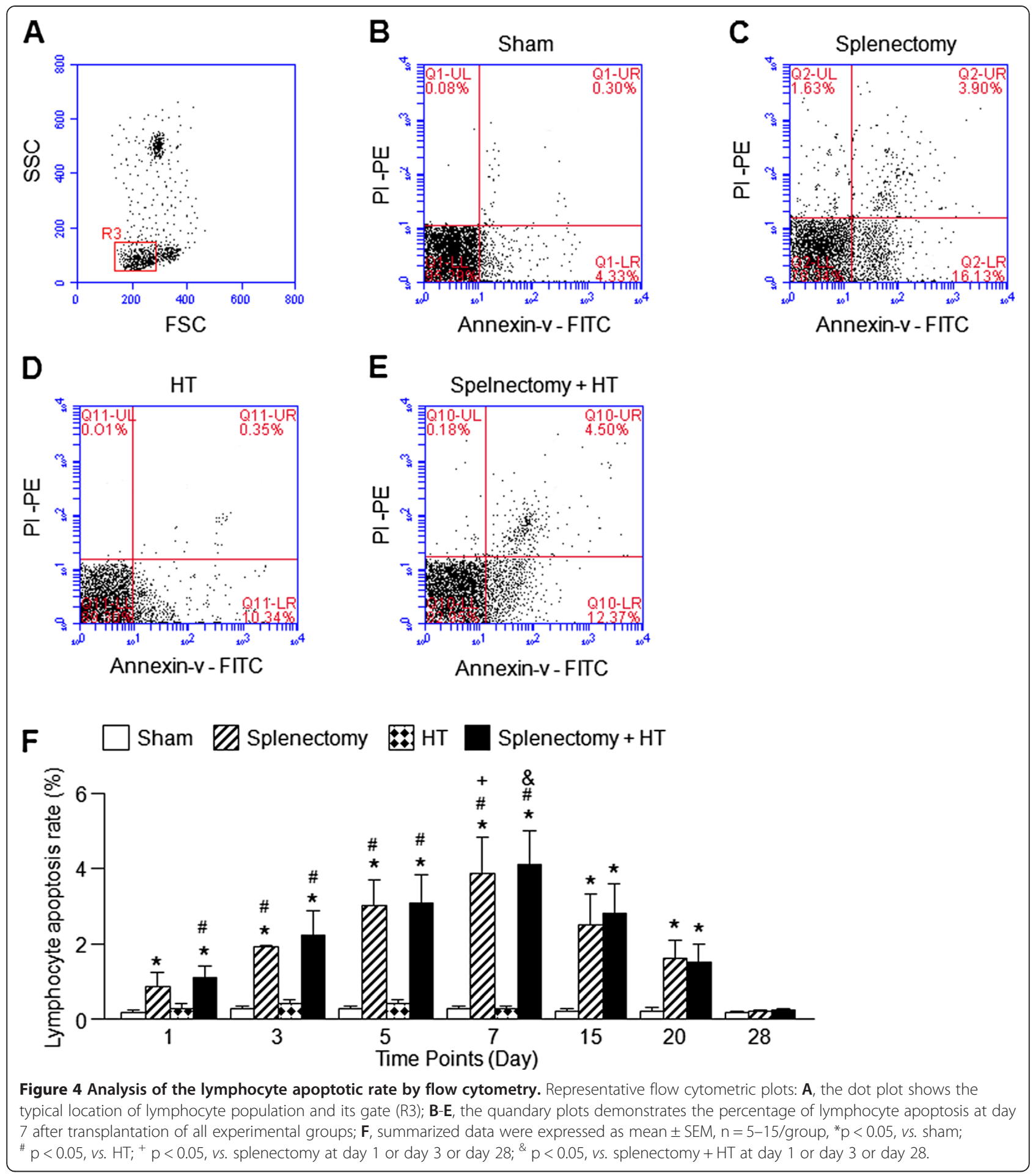

Representative flow cytometric panels demonstrated the rate of lymphocyte apoptosis within the gate (R3) in all experimental groups (Figure 4B - E) at day 7 after heart transplantation. We found that there was a higher rate of lymphocyte apoptosis (present in the upper right of the quarternary plot) in splenectomy and splenectomy + HT groups at day 7. Flow cytometric analysis revealed that the percentage of annexin- $\mathrm{v}^{+} \mathrm{PI}^{+}$expression cells was increased on day 3, 5, and 7 after the splenectomy surgery (day $7: 0.3 \pm 0.05 \%, 3.9 \pm 0.9 \%$ and $4.1 \pm 0.9 \%$ for sham, splenectomy and splenectomy + HT, respectively; $\mathrm{n}=15$ /group, sham vs. splenectomy or splenectomy + HT, p < 0.05). Then, the lymphocyte apoptotic rate was gradually decreased to baseline level in 
recipient rats on day $28(0.2 \pm 0.01 \%, 0.2 \pm 0.05 \%$ and $0.3 \pm 0.01 \%$ for sham, splenectomy and splenectomy $+\mathrm{HT}$, respectively; $\mathrm{n}=5$ /group, sham $v s$. splenectomy or splenectomy + HT, $p>0.05)$. There were neither significant differences in the percentages of annexin $-\mathrm{v}^{+} \mathrm{PI}^{+}$cells between sham and HT groups, nor between splenectomy and splenectomy + HT groups, indicating heart transplantation alone had no effect on lymphocyte apoptosis. These data were summarized in Figure 4F.

\section{Pathological changes of transplanted hearts}

The histopathology of heart allografts were assessed at different time points (day 3, 5, 7, 15, and 28) in HT and splenectomy + HT groups. Figure 5A shows the histology of a normal rat heart. At day 3, the transplanted hearts from HT group (Figure 5B) had interstitial edema and inflammatory cell infiltration, which were absent in the allograft hearts from splenectomy + HT group (Figure 5E). At day 5 , cardiomyocyte hemorrhage and an increasing number of inflammatory cell infiltrations were found in the transplanted hearts in HT group (Figure 5C). No pathologic change could be identified in the transplanted hearts from splenectomy + HT group (Figure 5F). At day 7, indications of severe rejections such as diffuse inflammatory infiltrate, myocardial cell necrosis, and destruction of myofibers appeared in the transplanted hearts from HT (Figure 5D), while there was mild cell infiltration in the myocardium of the allograft hearts from splenectomy + HT group (Figure 5G). At day 15, interstitial edema and increased inflammatory cell infiltration were observed in the allograft hearts collected from splenectomy + HT group (Figure $5 \mathrm{H}$ ). At day 28, the transplanted hearts collected from splenectomy + HT group were soft and partially gray-white with focal edema in the subepicardium. Upon examination with a microscope, severe rejection of the transplanted hearts showed myocardial cell necrosis and destruction of myofibers (Figure 5I).

\section{Discussion}

The major finding of the present study is that splenectomy can suppress the development of pathology and prolong the mean survival time of the cardiac allograft. Our data suggested that splenectomy plays a critical role in the development of immune tolerance in heart transplantation by increasing the level of $\mathrm{CD}_{4}{ }^{+} \mathrm{CD}_{25}{ }^{+}$Tregs and promoting the apoptosis of lymphocytes.
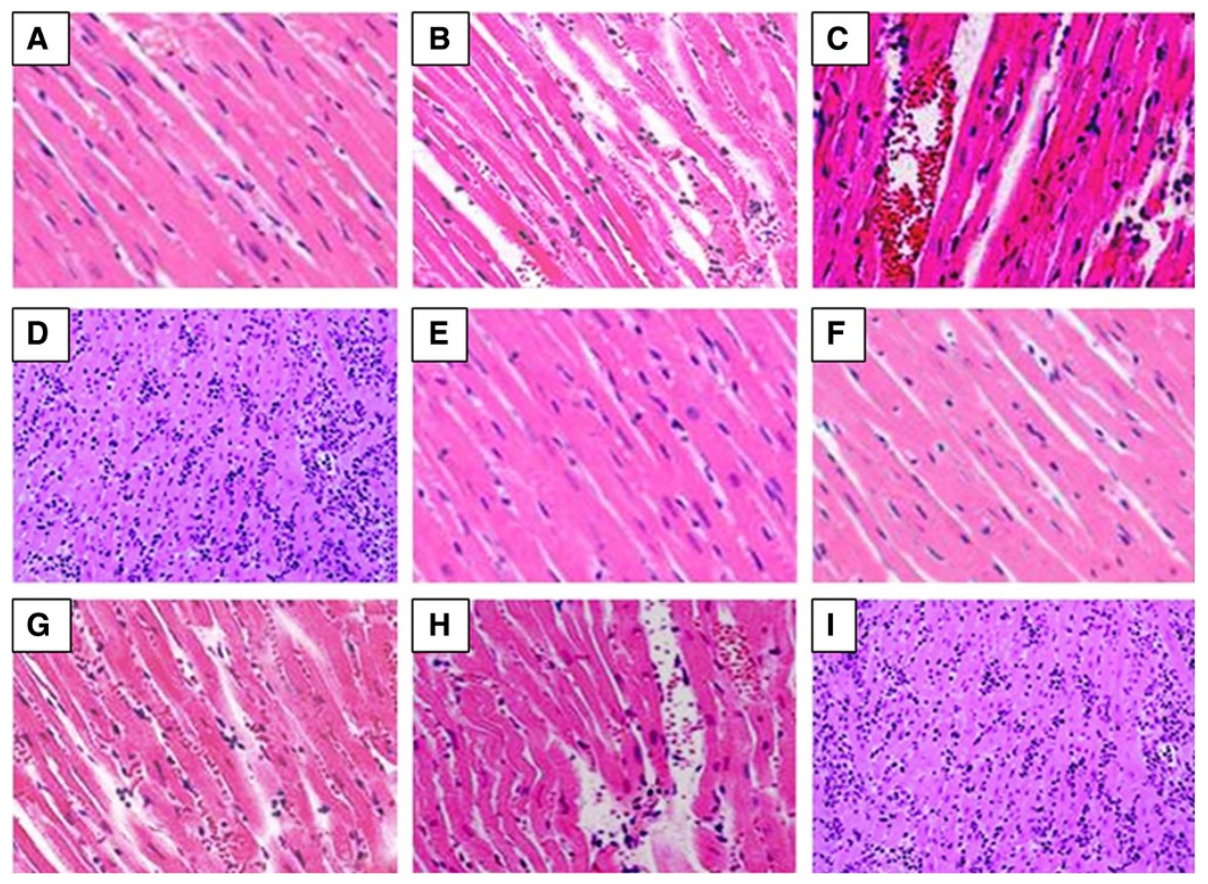

Figure 5 Histological assessment of transplanted hearts. Representative images of H\&E staining (all magnifications: 20x): A, a heart section from a donor rat showing the normal structure of cardiac myofibers; B-D, heart sections collected from HT group at different time point; $\mathbf{B}$, interstitial edema and inflammatory cell infiltration were observed on day 3 after transplantation; $\mathbf{C}$, cardiomyocyte hemorrhage and an increasing number of inflammatory cell infiltrations were found on day 5 after transplantation; D, diffuse inflammatory infiltrate, myocardial cell necrosis, and destruction of myofibers were observed on day 7 after transplantation; E-I, heart sections collected from splenectomy + HT group at different time point; $\mathbf{E - F}$, no pathology changes could be observed on days 3 and 5 after transplantation; $\mathbf{G}$, mild interstitial edema and cellular infiltration was seen in the myocardium on day 7 after transplantation; $\mathbf{H}$, cardiomyocyte interstitial edema and an increasing inflammatory cell infiltration could be observed on day 15 after transplantation; I, myocardial cell necrosis and destruction of myofibers were observed on day 28 after transplantation. 
Graft rejection by the immune system is a major cause of transplant failure. As we know, the largest lymphatic organ, the spleen, provides an immune microenvironment which accepts antigen stimulation and causes an immune response. Therefore, splenectomy is able to eliminate a primary immune response to an allograft. An earlier study [8] has reported that splenectomy is beneficial for xenograft survival by blocking the humoral antibody response.

The $\mathrm{CD} 4{ }^{+} \mathrm{CD} 25^{+}$Tregs, which constitute $5-10 \%$ of peripheral $\mathrm{CD}^{+}{ }^{+} \mathrm{T}$ cells in mice and humans, are recognized as a major subset of immune cells possessing potent suppressive properties [14,15]. A study on a thymectomised mouse model showed that $\mathrm{CD} 44^{+} \mathrm{CD} 25^{+}$ Tregs can prevent autoimmunity and allergy [16]. Moreover, several transplantation studies $[7,8]$ have demonstrated that $\mathrm{CD}_{4}{ }^{+} \mathrm{CD}_{25}{ }^{+}$Tregs can effectively prevent transplantation rejection by blocking the initiation of the immune response against the graft and actively participating in the regulation of the immune tolerance. In consistence with those reports, we found that the level of $\mathrm{CD}_{4}{ }^{+} \mathrm{CD}_{25}{ }^{+}$Tregs was significantly elevated within the first 7 days after the splenectomy surgery and gradually decreased to the baseline level, and the histopathologic change of transplanted hearts was milder and the mean survival time of transplanted hearts was longer in splenectomized rats. The possible explanation of this phenomenon was that accumulation of $\mathrm{CD}_{4}{ }^{+} \mathrm{CD}_{25}{ }^{+}$ Tregs inhibited the activation of naive $\mathrm{T}$ cells of the recipient, creating a permissive environment for graft acceptance. That is why $\mathrm{CD}_{4}{ }^{+} \mathrm{CD}_{25}{ }^{+}$Tregs were increased in the early days (within 7 days) after the splenectomy. However, due to some of the $\mathrm{CD}_{4}{ }^{+} \mathrm{CD}_{25}{ }^{+}$Tregs being generated from the $\mathrm{CD}_{4}{ }^{+} \mathrm{CD}_{25}$ - population in the adoptive system in the spleen $[17,18]$, the $\mathrm{CD}_{4}{ }^{+} \mathrm{CD}_{25}$ population was decreased after the splenectomy, which could explain why the $\mathrm{CD}_{4}{ }^{+} \mathrm{CD}_{25}{ }^{+}$Tregs were gradually back to the normal level later.

The mechanisms responsible for $\mathrm{CD}_{4}{ }^{+} \mathrm{CD}_{25}{ }^{+}$Tregs immunity suppression are not fully understood, and many of these mechanisms remain controversial $[6,19]$. Some observations have shown that one of the immunesuppression mechanisms was $\mathrm{CD}_{4}{ }^{+} \mathrm{CD}_{25}{ }^{+}$Tregs induced apoptosis of the immune cells [20-24]. Since lymphocyte apoptosis is an important immunoregulatory mechanism for maintaining homeostasis in the immune system in vivo [25-27], which could be an effective strategy to reduce transplantation rejection. Sharland et al. [28] reported that tolerant rats had higher numbers of apoptotic activated $\mathrm{T}$ cells in a liver transplantation model. In this study, we found that splenectomy regulated the immune homeostasis in vivo by increasing the rate of lymphocyte apoptosis. The flow cytometric results demonstrated that the rate of lymphocyte apoptosis was significantly increased in the splenectomized rats within the first 7 days after the splenectomy surgery and gradually decreased to baseline level. At the same time, this increased apoptosis tendency paralleled the raised level of $\mathrm{CD}_{4}{ }^{+} \mathrm{CD}_{25}{ }^{+}$Tregs. These data are in agreement with the previous findings [21-23,28].

In this study, we first reported that splenectomy prolonged the survival time of cardiac allograft by enhancing the immune tolerance via raising the level of $\mathrm{CD}_{4}{ }^{+} \mathrm{CD}_{25}{ }^{+}$Tregs and increasing the apoptotic rate of lymphocyte. The spleen has several unique functions in the immune system concerning not only the $\mathrm{CD}_{4}{ }^{+} \mathrm{CD}_{25}{ }^{+}$ Tregs, but also various kinds of cytokines such as interleukin-10 and transforming growth factor (TGF)- $\beta$. Our future study on these cytokines will better ascertain the immunomodulatory role of splenectomy in the cardiac allograft.

\section{Conclusions}

Our data indicate that splenectomy inhibits the development of pathology and prolongs the survival time of cardiac allograft. The responsible mechanism is associated with the induction of immune tolerance via elevating $\mathrm{CD}_{4}{ }^{+} \mathrm{CD}_{25}{ }^{+}$Tregs and increasing lymphocyte apoptosis.

\section{Competing interest}

There is no competing interest.

\section{Authors' contributions}

JZ, YC and ZY participated in research design; JZ, WZ, PL and RM performed the experiments; JZ, JW, SC, YC and ZY participated in the writing of the manuscript; JZ, JW, SC, CZ, YC and ZY participated in data analysis. All authors read and approved the final manuscript.

\section{Acknowledgements}

This work was supported by Sanya City Special Fund for Scientist Development, \# YW1205. We thank Michelle Durrant in the School of Medicine, Wright State University, for proofreading the manuscript.

\section{Author details}

'Department of Cardiothoracic Surgery, The People's Hospital of Sanya, Sanya, Hainan 572000, China. ²Department of Cardiology, The People's Hospital of Sanya, Sanya, Hainan 572000, China. ${ }^{3}$ Department of Pharmacology, The People's Hospital of Sanya, Sanya, Hainan 572000, China ${ }^{4}$ Department of Pharmacology and Toxicology, Boonshoft School of Medicine of Wright State University, Dayton, OH 45435, USA.

Received: 5 November 2012 Accepted: 14 May 2013

Published: 16 May 2013

\section{References}

1. Patel JK, Kittleson M, Kobashigawa JA: Cardiac allograft rejection. Surgeon 2011, 9:160-167.

2. Sun Y, Chen X, Zhao J, Zou X, Li G, Li X, Shen B, Sun S: Combined use of rapamycin and leflunomide in prevention of acute cardiac allografts rejection in rats. Transpl Immunol 2012, 27:19-24.

3. Fu F, Li Y, Qian S, Lu L, Chambers F, Starzl TE, Fung JJ, Thomson AW: Costimulatory molecule-deficient dendritic cell progenitors (MHC class II+, CD80dim, CD86-) prolong cardiac allograft survival in nonimmunosuppressed recipients. Transplantation 1996, 62:659-665.

4. Lindenfeld J, Miller GG, Shakar SF, Zolty R, Lowes BD, Wolfel EE, Mestroni L, Page RL, Kobashigawa J: Drug therapy in the heart transplant recipient: part II: immunosuppressive drugs. Circulation 2004, 110:3858-3865.

5. Sakaguchi S, Sakaguchi N, Asano M, Itoh M, Toda M: Immunologic selftolerance maintained by activated T cells expressing IL-2 receptor alpha- 
chains (CD25). Breakdown of a single mechanism of self-tolerance causes various autoimmune diseases. J Immunol 1995, 155:1151-1164.

6. Graca L, Thompson S, Lin CY, Adams E, Cobbold SP, Waldmann H: Both $\mathrm{CD} 4(+) \mathrm{CD} 25(+)$ and $\mathrm{CD} 4(+) \mathrm{CD} 25(-)$ regulatory cells mediate dominant transplantation tolerance. J Immunol 2002, 168:5558-5565.

7. Thomas F, Thomas J, Wolf JS, Schatzki P, Cohen C, Hume DM: Prevention of hyperacute kidney rejection by early splenectomy: etiologic and therapeutic implications. Surg Forum 1972, 23:261-263.

8. Carobbi A, Araneda D, Thomas F, Quarantillo P, Thomas J: Splenectomy is a potent immunosuppressive modality for cardiac xenografting. Transplant Proc 1993, 25:419-420.

9. Schwarz RE, Hiserodt JC: Effects of splenectomy on the development of tumor-specific immunity. J Surg Res 1990, 48:448-453.

10. Ono K, Lindsey ES: Improved technique of heart transplantation in rats. J Thorac Cardiovasc Surg 1969, 57:225-229.

11. Schmid C, Binder J, Heemann U, Tilney NL: Successful heterotopic heart transplantation in rat. Microsurgery 1994, 15:279-281

12. Fingerhuth $\mathrm{H}$, Holschermann $\mathrm{H}$, Grimm $\mathrm{H}$, Tillmanns $\mathrm{H}$, Haberbosch W, Braun-Dullaeus RC, Stadlbauer TH: 3-Deazaadenosine prevents leukocyte invasion by suppression of adhesion molecule expression during acute cardiac allograft rejection: involvement of apoptotic cell death. J Heart Lung Transplant 2004, 23:970-978.

13. Chen J, Chen S, Chen Y, Zhang C, Wang J, Zhang W, Liu G, Zhao B, Chen Y: Circulating endothelial progenitor cells and cellular membrane microparticles in $\mathrm{db} / \mathrm{db}$ diabetic mouse: possible implications in cerebral ischemic damage. Am J Physiol Endocrinol Metab 2011, 301:E62-E71.

14. Sakaguchi $\mathrm{S}$ : Naturally arising Foxp3-expressing $\mathrm{CD} 25+\mathrm{CD} 4+$ regulatory $T$ cells in immunological tolerance to self and non-self. Nat Immunol 2005, 6:345-352

15. Levings MK, Sangregorio R, Roncarolo MG: Human $c d 25(+) c d 4(+)$ t regulatory cells suppress naive and memory $T$ cell proliferation and can be expanded in vitro without loss of function. J Exp Med 2001, 193:1295-1302.

16. Shevach EM: Regulatory T cells in autoimmmunity. Annu Rev Immunol 2000, 18:423-449.

17. Chen W, Jin W, Hardegen N, Lei KJ, Li L, Marinos N, McGrady G, Wahl SM: Conversion of peripheral CD4+. J Exp Med 2003, 198:1875-1886.

18. Curotto de Lafaille MA, Lino AC, Kutchukhidze N, Lafaille JJ: CD25- T cells generate CD25+Foxp3+ regulatory T cells by peripheral expansion. J Immunol 2004, 173:7259-7268.

19. Piccirillo CA, Letterio JJ, Thornton AM, McHugh RS, Mamura M, Mizuhara $H_{4}$ Shevach EM: CD4(+)CD25(+) regulatory T cells can mediate suppressor function in the absence of transforming growth factor beta1 production and responsiveness. J Exp Med 2002, 196:237-246.

20. Dai Z, Li Q, Wang Y, Gao G, Diggs LS, Tellides G, Lakkis FG: CD4 + CD25+ regulatory $T$ cells suppress allograft rejection mediated by memory CD8+ $T$ cells via a CD30-dependent mechanism. J Clin Invest 2004, 113:310-317.

21. Janssens W, Carlier V, Wu B, VanderElst L, Jacquemin MG, Saint-Remy JM: CD4 + CD25+ T cells lyse antigen-presenting $B$ cells by Fas-Fas ligand interaction in an epitope-specific manner. J Immunol 2003, 171:4604-4612.

22. Venet F, Pachot A, Debard AL, Bohe J, Bienvenu J, Lepape A, Powell WS, Monneret G: Human CD4 + CD25+ regulatory T lymphocytes inhibit lipopolysaccharide-induced monocyte survival through a Fas/Fas liganddependent mechanism. J Immunol 2006, 177:6540-6547.

23. Grossman WJ, Verbsky JW, Barchet W, Colonna M, Atkinson JP, Ley TJ: Human T regulatory cells can use the perforin pathway to cause autologous target cell death. Immunity 2004, 21:589-601.

24. Zhang ZX, Yang L, Young K, DuTemple B, Zhang L: Identification of a previously unknown antigen-specific regulatory $T$ cell and its mechanism of suppression. Nat Med 2000, 6:782-789.

25. Gonzalez N, Bensinger SJ, Hong C, Beceiro S, Bradley MN, Zelcer N, Deniz J, Ramirez C, Diaz M, Gallardo G, et al: Apoptotic cells promote their own clearance and immune tolerance through activation of the nuclear receptor LXR. Immunity 2009, 31:245-258.

26. Radu CG, Shu CJ, Nair-Gill E, Shelly SM, Barrio JR, Satyamurthy N, Phelps ME, Witte ON: Molecular imaging of lymphoid organs and immune activation by positron emission tomography with a new [18F]-labeled 2'deoxycytidine analog. Nat Med 2008, 14:783-788.

27. Rothlin CV, Ghosh S, Zuniga El, Oldstone MB, Lemke G: TAM receptors are pleiotropic inhibitors of the innate immune response. Cell 2007, 131:1124-1136.
28. Sharland A, Yan Y, Wang C, Bowen DG, Sun J, Sheil AG, McCaughan GW, Bishop GA: Evidence that apoptosis of activated T cells occurs in spontaneous tolerance of liver allografts and is blocked by manipulations which break tolerance. Transplantation 1999, 68:1736-1745.

doi:10.1186/1749-8090-8-129

Cite this article as: Zhu et al:: Splenectomy increases the survival time of heart allograft via developing immune tolerance. Journal of Cardiothoracic Surgery 2013 8:129.

\section{Submit your next manuscript to BioMed Central and take full advantage of:}

- Convenient online submission

- Thorough peer review

- No space constraints or color figure charges

- Immediate publication on acceptance

- Inclusion in PubMed, CAS, Scopus and Google Scholar

- Research which is freely available for redistribution 